\title{
E-Cigarettes: The Science Behind the Smoke and Mirrors
}

\author{
Nathan K Cobb MD and Rajiv Sonti MD
}

\author{
Introduction \\ Review of the Literature \\ Device Construction and Functioning \\ Epidemiology \\ Efficacy \\ Safety, Harm Reduction, and Regulation \\ Summary
}

\begin{abstract}
E-cigarettes are a diverse set of devices that are designed for pulmonary delivery of nicotine through an aerosol, usually consisting of propylene glycol, nicotine, and flavorings. The devices heat the nicotine solution using a battery-powered circuit and deliver the resulting vapor into the proximal airways and lung. Although the current devices on the market appear to be safer than smoking combusted tobacco, they have their own inherent risks, which remain poorly characterized due to widespread product variability. Despite rising use throughout the United States, predominantly by smokers, limited evidence exists for their efficacy in smoking cessation. Pending regulation by the FDA will enforce limited disclosures on the industry but will not directly impact safety or efficacy. Meanwhile, respiratory health practitioners will need to tailor their discussions with patients, taking into account the broad range of existing effective smoking cessation techniques, including pharmaceutical nicotine replacement therapy. Key words: e-cigarettes; cigarettes; smoking cessation; nicotine replacement; regulation; safety; harm reduction. [Respir Care 2016;61(8):1122-1128. (C) 2016 Daedalus Enterprises]
\end{abstract}

\section{Introduction}

The term "e-cigarette" is used to refer to an array of devices marketed in the United States and internationally

The authors are affiliated with the Division of Pulmonary, Critical Care, and Sleep Medicine, Department of Medicine, MedStar Georgetown University Medical Center, Washington, DC.

The authors have disclosed no conflicts of interest.

Dr Cobb presented a version of this paper as the 31st Philip Kittredge Memorial Lecture at the 61st AARC Congress, held November 7-10, 2015, in Tampa, Florida.

Correspondence: Nathan K Cobb MD, MedStar Georgetown University Medical Center, Main Building, 4th Floor, 3800 Reservoir Road, NW, Washington, DC 20007. E-mail: nkc4@georgetown.edu.

DOI: $10.4187 /$ respcare.04944 that vaporize a nicotine-containing solution for inhalation. The first e-cigarette is thought to have been invented in Hong Kong in the early 2000s and reached the United States shortly thereafter in small numbers. In recent years, however, their use and popularity have exploded. By 2014 there were $>450$ different brands of e-cigarettes, ${ }^{1} 6$ tobacco companies had acquired or developed their own device, ${ }^{2}$ and $12.6 \%$ of United States adults ${ }^{3}$ along with $13.4 \%$ of high school students ${ }^{4}$ had tried an e-cigarette. However, concurrent with this rapid rise in use have been increasing questions about their safety, efficacy, and potential impact on public health.

Beginning in August 2016, e-cigarettes will be subject to recently announced regulations by the FDA, although the rules are currently subject to legal challenge from the e-cigarette industry. While they are often assumed to contain pharmaceutical or food-grade chemicals, no rules, current or pending, require that devices labeled "e-cigarettes" 


\section{E-Cigarettes: The Science Behind the Smoke and Mirrors}

do contain pharmaceutical or food-grade chemicals, and no regulations directly address their safety or efficacy. This may be in part because both the academic and public health communities are split on their perceived safety and potential impact. A recent review by Public Health England asserted that e-cigarettes are "95\% less harmful [to one's] health than normal cigarettes," 5 based on the absence of constituent chemicals found in combusted tobacco, whereas the American Lung Association ${ }^{6}$ has recommended against their use for cessation, and other organizations have called for further study ${ }^{7}$ or more aggressive regulation. ${ }^{8}$

Although many people report using e-cigarettes for smoking cessation, their efficacy has not been demonstrated in randomized clinical trials. ${ }^{9,10}$ Despite this, the devices are notably similar to pharmaceutical nicotine replacement therapy products, such as gums, lozenges, patches, nasal sprays, and inhalers, ${ }^{11}$ and may ultimately prove to be part of the same class. Meanwhile, researchers and public professionals have raised an array of concerns about their introduction into the market, including "renormalization" of smoking behavior, serving as a gateway to smoking for youth, ${ }^{12}$ and delaying cessation in people who might otherwise quit. ${ }^{13}$

For the most part, e-cigarettes do not contain the chemicals in combusted tobacco smoke that have been tied to cancer and respiratory disease. On the other hand, little is known about the impact of the chemicals that are present in nicotine solutions and their impact after heating, aerosolization, and inhalation into the respiratory system. Despite the limited knowledge base and the concerns that have been raised, e-cigarettes continue to proliferate and may ultimately play a significant role in transitioning smokers away from combusted tobacco. Here we aim to review what is known about e-cigarette design and their impact on respiratory and cardiac health, along with a discussion of the limited evidence on safety and efficacy, in an effort to provide context for the inevitable questions and concerns from patients and colleagues.

\section{Review of the Literature}

\section{Device Construction and Functioning}

The earliest and most common models of e-cigarettes were designed as look-alikes for traditional combusted cigarettes. In general, these basic models have a cylindrical body with a mouthpiece at one end and an LED light at the other designed to mimic a lit cigarette. ${ }^{14}$ General construction consists of the body, a cartridge containing nicotine solution, a heating element, and a battery. These models may be referred to in terms such as "cigalikes," whereas later models diverge significantly, adapting larger batteries and reservoirs (or "tanks") for nicotine solution in lieu of the cartridge ${ }^{2}$ and frequently abandoning the LED or other efforts to appear similar to a cigarette or cigar.

On inhalation, a pressure- or flow-sensitive switch closes and connects the battery to both the LED and the heating element. The nicotine solution is brought into contact with the heating element through a wicking mechanism, from either the tank or the cartridge. The heating element vaporizes the liquid, and the aerosol is then drawn through the mouthpiece into the lungs. Tank models often replace the pressure switch in earlier models with a manual one, allowing the user to begin the vaporization process before inhalation. This eliminates the initial lack of vapor draw present with a flow switch.

Although a great deal has been published in the academic literature about device construction, solution constituents, and aerosol contents, the lack of regulation enforcing consistency limits our ability to make generalizations about e-cigarettes. In other words, the next generation of devices could differ substantially from the current ones, ranging from the appearance of the devices to their mechanism of vaporization to their choice of solution chemicals and even the amount of nicotine delivered.

Nicotine Solutions. Whereas most manufacturers use propylene glycol as a base solution (or "humectant"), others have used glycerol (ie, glycerin or glycerine) or other chemicals. Propylene glycol is generally accepted as safe in cosmetics and foodstuffs but has not been extensively studied as an inhalant or for long-term use. ${ }^{15}$ Solutions are sold both in prefilled cartridges and as stand-alone preparations designed to fill tanks or refill used cartridges. These solutions can be purchased directly from e-cigarette manufacturers, online from independent vendors, or at local "vape shops" that may mix their own solutions.

Analysis of commercially sold liquids has demonstrated variable results in the United States market, with earlier testing having more common findings of contamination and lower grade materials. Recent testing of the solutions from 2 major vendors showed few impurities and a profile consistent with the use of pharmaceutical grade nicotine. ${ }^{16}$ On the other hand, the first published analysis of an e-cigarette solution demonstrated contamination with diethylene glycol in a single sample. ${ }^{17}$ This finding spurred early concerns about supply chain control ${ }^{18}$ because diethylene glycol has been a lethal and toxic contaminant in multiple mass poisonings in emerging markets. ${ }^{19}$ Many devices and their refill solutions are imported from China; analysis of solutions on the Chinese market found primarily propylene glycol, glycerol, and tobacco-specific impurities in addition to nicotine and flavorings consistent with United States findings. ${ }^{20}$

Importantly, nicotine content in e-cigarette solutions has also been variable, often not matching labeling. ${ }^{21}$ Some 


\section{E-Cigarettes: The Science Behind the Smoke and Mirrors}

vendors sell highly concentrated solutions, either designed for direct use or dilution with propylene glycol by the purchasers. These solutions have raised concerns for potential poisonings, ${ }^{22}$ especially given the rise in number of calls to poison centers since the introduction of e-cigarettes. ${ }^{23}$

Particulate Matter and Effects on the Respiratory System. Current understanding of e-cigarette impact on human physiology is derived primarily from analysis of nicotine solutions and the emitted vapor and secondarily from a small number of studies of nicotine delivery and its associated physiologic response. For the most part, studies have used devices with propylene glycol-based solutions. To date, there are no studies of the impact of e-cigarettes on long-term respiratory health.

Of particular concern has been the heating process to vaporize the solution. Little is known about the long-term inhalation of propylene glycol in vapor form. ${ }^{15}$ When propylene glycol or glycerol is directly heated, toxic aldehydes such as formalin (a significant known carcinogen), ${ }^{24}$ acetaldehyde, and acrolein are naturally formed in a secondary reaction. ${ }^{25}$ Increased heating element temperature coupled with inadequate solution delivery to the heating element has been associated with higher levels of aldehydes $^{24}$ in device testing. In addition to known toxins, many organic compounds within the aerosol are unidentifiable. ${ }^{26}$ These compounds, complexed into particles that compose the aerosol, are of a size distribution closely mirroring cigarette smoke ${ }^{27}$ and theoretically can reach the distal bronchioles and alveoli. ${ }^{28}$

Cell culture models have demonstrated a cytotoxic effect of certain e-cigarette aerosols. For example, one experiment demonstrated necrotic cell death in addition to lower macrophage and neutrophil function in an in vitro model of 2 separate human epithelial cell lines. ${ }^{29}$ Additionally, once infected with bacteria, those cells exposed harbored the organisms at a higher concentration. Other studies have only uncovered cytotoxicity using particular brands or flavors ${ }^{30}$ or cell types. ${ }^{31}$ Finally, one study demonstrated no cytotoxicity but did show increased concentration of an inflammatory mediator (interleukin-6) in cells exposed to e-cigarette solution. ${ }^{32}$

There is limited information about the impact of e-cigarettes on respiratory mechanics. One study of cigarette smokers without lung disease who used e-cigarettes ad lib for $5 \mathrm{~min}$ found that device use worsened airway impedance, lung resistance, and peripheral pulmonary resistance measured with special equipment. ${ }^{33}$ Despite these changes, spirometry was unchanged in the study, making interpretation of the short-term findings difficult. Other investigators have specifically noted that $\mathrm{FEV}_{1} / \mathrm{FVC}$ changes with exposure to combusted cigarette smoke but not e-cigarette vapor. ${ }^{34}$
Secondhand smoke is a real and substantial risk with the use of combusted cigarettes, whereas its risk with e-cigarettes is unclear, if present. E-cigarettes generally produce vapor only on inhalation, and the exhaled vapor contains levels of nicotine and volatile organic compounds markedly lower than those in true tobacco smoke. ${ }^{35}$

Nicotine Delivery, Deposition, and Uptake. The cardiovascular impact of combusted tobacco smoke has a complex set of considerations related primarily to carbon monoxide and other combustion products. Thrombosis, platelet activation, and inflammation contribute to reduced myocardial blood supply, which is compounded by reduced oxygen delivery from carbon monoxide. Nicotine increases heart rate and blood pressure, driving up myocardial demand, synergistically increasing the risk of cardiac ischemia in the setting of tobacco smoke. ${ }^{36}$ Critically, however, nicotine is considered to be safe when delivered alone as pharmaceutical nicotine replacement therapy. ${ }^{11}$

As expected, heart rate increases with exposure to ecigarette vapor as plasma nicotine levels rise. ${ }^{37,38}$ For smokers trying e-cigarettes for the first time, plasma nicotine levels generally track with increasing solution nicotine concentrations. ${ }^{39}$ However, more experienced users appear to learn how to inhale differently, with longer "puffs" 40 and can generate higher plasma nicotine levels. ${ }^{41}$

Early studies using primarily first generation e-cigarettes showed that they delivered low or even negligible plasma levels of nicotine. ${ }^{38,42}$ Later studies, particularly in experienced users, have shown nicotine plasma concentrations similar to those of combusted tobacco cigarettes. ${ }^{41,43}$ The rapid evolution in nicotine delivery is probably multifactorial, related not only to optimized solutions and devices capable of delivering higher concentrations of nicotine in the vapor, but also to increasing aerosol deposition into the lungs and distal alveoli while bypassing the oral airway. Nevertheless, although e-cigarette aerosol has a particle size distribution similar to that of combusted tobacco smoke, ${ }^{28}$ serum testing has indicated a slower uptake of nicotine into plasma. ${ }^{43}$ This probably indicates that the deposition still remains predominantly in the oral mucosa and oral airways rather than the alveoli and that absorption is into the venous circulation rather than arterial.

\section{Epidemiology}

As of 2014, 12.6\% of United States adults report having tried an e-cigarette, including $49 \%$ of daily cigarette smokers, of whom $16 \%$ report currently using e-cigarettes as well. ${ }^{44}$ Use is more common in younger adults; $21.6 \%$ of people $18-24$ y old have tried e-cigarettes versus $3.7 \%$ of people $>65$ y old. ${ }^{3}$ Individuals who report recently quitting tobacco are significantly more likely to report active use of e-cigarettes, with $22 \%$ of recent quitters reporting 


\section{E-Cigarettes: The Science Behind the Smoke and Mirrors}

use versus $3.7 \%$ of all adults. ${ }^{44}$ Overall, use of e-cigarettes by adults is primarily limited to smokers and recent former smokers, with only $0.4 \%$ of never smokers and $0.8 \%$ of smokers quitting $>4$ y prior reporting e-cigarette use. ${ }^{44}$

E-cigarette use appears to be increasing among in young adults. $13.4 \%$ of high school students tried an e-cigarette in 2014 ( 2 million students), up from $4.5 \%$ in 2013 and $1.5 \%$ in 2011. Concurrent with the increase in reported e-cigarette use has been a drop in the use of combusted cigarettes, whereas e-cigarette use exceeds combusted cigarette use across all ages. ${ }^{4}$ The vast majority of adolescents who regularly use e-cigarettes are already using combusted cigarettes. ${ }^{45}$ However, concern remains that e-cigarettes may serve as a low-risk and palatable gateway to combusted tobacco use, ${ }^{46}$ ultimately increasing morbidity rather than decreasing it.

\section{Efficacy}

Decades of research on nicotine replacement therapy have demonstrated that multiple forms of delivery, including the patch, gum, lozenge, nasal spray, and inhaler, can be made both safe and effective. ${ }^{11}$ Given history and the relative similarity between e-cigarettes and other forms of nicotine replacement therapy, there is little reason to believe that a nicotine inhaler using propylene glycol and refined nicotine cannot be constructed to be effective for smoking cessation. However, existing nicotine replacement therapy products were developed within formal pharmaceutical processes and marketed and sold under governmental regulation, whereas to date, randomized control trials of e-cigarettes from various manufacturers have failed to demonstrate efficacy. Of the 3 meta-analyses in press, 2 found a probable increase in cessation, ${ }^{47,48}$ whereas a third, ${ }^{49}$ taking into account more non-controlled and observational trials, found that they may suppress cessation, indicating that the current literature is insufficient to make firm conclusions in either direction.

Two randomized trials have directly addressed cessation. A New Zealand-based trial randomized participants to a first generation electronic cigarette with $16 \mathrm{mg}$ of nicotine, a placebo device, or access to nicotine patches. Trial participants were provided with electronic cigarettes or given vouchers to obtain their own nicotine replacement. The trial found no significant effect for the nicotine e-cigarette (or for patch vouchers) over placebo. In the second trial, conducted in Italy, smokers not intending to quit were randomized to 3 conditions: a placebo device, a commercial e-cigarette model, or the same model followed by a taper. Although cessation rates were higher in the nicotine arms (13 and 9\%) than for placebo (4\%), the results were not statistically significant. The pooled results of these 2 trials indicate that nicotine-containing e-cigarettes outperform placebo e-cigarettes (RR 2.29). ${ }^{47,48}$ No- tably, both of these trials used early generations of e-cigarettes with a lower delivery of nicotine than current devices on the market.

In the only randomized controlled trial conducted in the United States, investigators randomized smokers interested in cutting back on smoking to either nicotine-containing e-cigarettes or placebo. At 3 weeks, participants receiving the nicotine e-cigarette were smoking slightly fewer combusted cigarettes, and the reduction was directly related to the number of nicotine-containing e-cigarettes used. ${ }^{50}$

Taken together in context, these trials are consistent with the theory that e-cigarettes can potentially be effective, but reinforce the limitation that there is no true class effect. In other words, the broad variability in functioning and nicotine delivery across manufacturers and device evolution precludes assumptions about any single device based on studies of competitors. Currently, no individual device has been demonstrated to be effective, and no class effect across devices should be assumed.

\section{Safety, Harm Reduction, and Regulation}

There is little real debate that the majority of devices on the market are less harmful than the use of combusted tobacco. Based on constituent analysis, e-cigarettes have been estimated to have a relative harm profile somewhere between nicotine replacement therapy ( $2 \%$ of cigarette smoke) and oral tobacco use (5\% of cigarette smoke), ${ }^{51}$ in other words $\geq 20$-fold less dangerous than cigarette smoke. Given this, it seems more appropriate to compare safety expectations with pharmaceutical products that are also constructed with refined chemicals rather than processed tobacco.

To date, most short-term adverse effects have occurred due to poor manufacturing standards. Battery explosions, ${ }^{52,53}$ solution contaminations, ${ }^{54}$ and high levels of toxic by-products due to higher heating element temperatures have all been reported. ${ }^{24,55}$ Although these problems have led to serious complications ranging from third degree burns and ICU admissions ${ }^{53}$ to lipoid pneumonia, ${ }^{56}$ they are also the most straightforward because they have been solved in other products (such as pharmaceuticals, cosmetics, pet foods, and children's toys) through regulation and supply chain management. Of greater concern are the unknown long-term consequences of inhalation of propylene glycol and flavorings, compounded with the risk that e-cigarettes may evolve in directions inconsistent with their currently known profile.

At the moment, the FDA has put forward a fairly minimalist set of regulations for e-cigarettes..$^{57}$ The regulations will subject e-cigarettes to the same level of scrutiny as tobacco products, including restricted marketing toward youth, warning labels, evidence-supported claims about modified risk, and disclosure of ingredients. ${ }^{58}$ Rules to 


\section{E-Cigarettes: The Science Behind the Smoke and Mirrors}

prevent youth access go into effect in the summer of 2016 while other rules will be phased in over the next 2 years. Importantly, these proposed regulations would not enforce manufacturing standards, require supply chain management techniques, eliminate contaminants, cap heating element temperatures, or otherwise address many of the known short-term harms. What is currently unclear is how the FDA will enforce "premarket" review of newly developed e-cigarettes, an expensive and time-consuming process that could potentially favor larger manufacturers and existing legacy combusted cigarette producers with deeper pockets.

Rapid change in uptake profiles over the past several years indicates that the devices can be optimized, and there is no reason to believe that they have stopped evolving. In the long term, assuring safety for a product without tight definitions and regulatory oversight is difficult, particularly if the market consolidates around the existing multinational tobacco companies that need to protect existing combusted tobacco sales.

\section{Summary}

When this manuscript was written, a search for "e-cigarettes" on PubMed returned 1,795 papers, with nearly half of them published in the preceding 12 months. Despite the explosion of literature, we still can say little about any given device purchased in a convenience store: how well it might work to help a patient quit, whether its battery works properly, or whether its nicotine solution is uncontaminated. This is through no fault of the researchers but simply indicates that some of these questions may be impossible to answer concretely as long as what we call e-cigarettes remain such a broad and diverse class of products.

A common question to health-care practitioners is the simple "what should I do?" from patients, friends, and family alike. E-cigarettes are increasingly used by smokers for both cessation and harm reduction..$^{9,59}$ For those individuals who have successfully transitioned off of combusted tobacco, simple encouragement to wean off of ecigarettes and nicotine as tolerated makes more sense than abrupt cessation or an attempted transition to another form of nicotine replacement. The damage from continued, chronic inhalation of tobacco smoke, particularly in the respiratory patient, is immense and ongoing. Any tool that avoids that, whether nicotine replacement therapy, e-cigarettes, or otherwise, should be evaluated in that critical context. More difficult is the individual looking either to quit in the future or even simply to minimize their use of combusted tobacco without quitting. For these individuals, it is perhaps most useful to think of e-cigarettes as members of the nicotine replacement class, along with the patch, gum, and inhaler. At one end of this continuum are the pharmaceutical products that are safe, reliable, and effective, whereas at the other end are e-cigarettes that tend to be cheaper, more widely available, and heavily marketed and have higher consumer acceptance. Until e-cigarettes are regulated and standardized with clear evidence of efficacy, pharmaceutical products remain the more conservative choice and, under the Affordable Care Act, are also required to be covered without co-pay by insurers. ${ }^{60}$ How future regulation will impact e-cigarettes or whether manufacturers will choose to pursue optimization of their devices for cessation and clinical trials remains unknown. Regardless, the rapid ascent of e-cigarettes demonstrates the feasibility of substituting "clean" nicotine for toxic, combusted tobacco smoke at a population level and provides hope for future public health strategies.

\section{REFERENCES}

1. Zhu SH, Sun JY, Bonnevie E, Cummins SE, Gamst A, Yin L, Lee M. Four hundred and sixty brands of e-cigarettes and counting: implications for product regulation. Tob Control 2014;23(Suppl 3):iii3-9.

2. Grana R, Benowitz N, Glantz SA. E-cigarettes: a scientific review. Circulation 2014;129(19):1972-1986.

3. Schoenborn CA, Gindi RM. Electronic cigarette use among adults: United States, 2014. NCHS Data Brief 2015(217).

4. Arrazola RA, Singh T, Corey CG, Husten CG, Neff LJ, Apelberg BJ, et al. Tobacco use among middle and high school students: United States, 2011-2014. MMWR Morb Mortal Wkly Rep 2015;64(14): 381-385.

5. McNeill A, Brose LS, Calder R, Hitchman SC, Hajek P, McRobbie H. E-cigarettes: an evidence update. London, United Kingdom: Public Health England; 2015.

6. American Lung Association statement on e-cigarettes. http:// www.lung.org/our-initiatives/tobacco/oversight-and-regulation/ statement-on-e-cigarettes.html. Accessed March 23, 2016.

7. Brandon TH, Goniewicz ML, Hanna NH, Hatsukami DK, Herbst RS, Hobin JA, et al. Electronic nicotine delivery systems: a policy statement from the American Association for Cancer Research and the American Society of Clinical Oncology. Clin Cancer Res 2015; 21(3):514-25

8. Rojewski AM, Coleman NC, Toll BA. Emerging policy issues regarding electronic nicotine delivery systems: a need for regulation. http://www.sbm.org/UserFiles/file/e-cig-statement_v2_lores.pdf. Accessed 23 Mar 2016.

9. Pearson JL, Stanton CA, Cha S, Niaura RS, Luta G, Graham AL. E-cigarettes and smoking cessation: insights and cautions from a secondary analysis of data from a study of online treatment-seeking smokers. Nicotine Tob Res 2015;17(10):1219-1227.

10. Siu AL, U.S. Preventive Services Task Force. Behavioral and pharmacotherapy interventions for tobacco smoking cessation in adults, including pregnant women: U.S. Preventive Services Task Force recommendation statement. Ann Intern Med 2015;163(8):622-634.

11. Stead LF, Perera R, Bullen C, Mant D, Hartmann-Boyce J, Cahill K, Lancaster T. Nicotine replacement therapy for smoking cessation. Cochrane Database Syst Rev 2012;(11):CD000146.

12. Kalkhoran S, Glantz SA. Modeling the health effects of expanding e-cigarette sales in the United States and United Kingdom: A Monte Carlo analysis. JAMA Intern Med 2015;175(10):1671-1680.

13. Walton KM, Abrams DB, Bailey WC, Clark D, Connolly GN, Djordjevic MV, et al. NIH electronic cigarette workshop: developing a research agenda. Nicotine Tob Res 2015;17(2):259-269. 


\section{E-Cigarettes: The Science Behind the Smoke and Mirrors}

14. Brown CJ, Cheng JM. Electronic cigarettes: product characterisation and design considerations. Tob Control 2014;23(Suppl 2):ii4-10.

15. Wieslander G, Norbäck D, Lindgren T. Experimental exposure to propylene glycol mist in aviation emergency training: acute ocular and respiratory effects. Occup Environ Med 2001;58(10):649-655.

16. Flora JW, Meruva N, Huang CB, Wilkinson CT, Ballentine R, Smith DC, et al. Characterization of potential impurities and degradation products in electronic cigarette formulations and aerosols. Regul Toxicol Pharmacol 2016;74:1-11.

17. US Food and Drug Administration. Evaluation of e-cigarettes. May 4, 2009. http://www.fda.gov/downloads/Drugs/ScienceResearch/ UCM173250.pdf. Accessed Mar 6, 2010.

18. Cobb NK, Byron MJ, Abrams DB, Shields PG. Novel nicotine delivery systems and public health: the rise of the "e-cigarette". Am J Public Health 2010;100(12):2340-2342.

19. Schier JG, Rubin CS, Miller D, Barr D, McGeehin MA. Medicationassociated diethylene glycol mass poisoning: a review and discussion on the origin of contamination. J Public Health Policy 2009; 30(2):127-143.

20. Han S, Chen H, Zhang X, Liu T, Fu Y. Levels of selected groups of compounds in refill solutions for electronic cigarettes. Nicotine Tob Res 2016;18(5):708-714.

21. Goniewicz ML, Gupta R, Lee YH, Reinhardt S, Kim S, Kim B, et al. Nicotine levels in electronic cigarette refill solutions: a comparative analysis of products from the US, Korea, and Poland. Int J Drug Policy 2015;26(6):583-588.

22. Bassett RA, Osterhoudt $K$, Brabazon T. Nicotine poisoning in an infant. N Engl J Med 2014;370(23):2249-2250.

23. Chatham-Stephens K, Law R, Taylor E, Melstrom P, Bunnell R, Wang B, et al. Notes from the field: calls to poison centers for exposures to electronic cigarettes: United States, Sept 2010-Feb 2014. MMWR Morbid Mortal Wkly Rep 2014;63(13):292-293.

24. Gillman IG, Kistler KA, Stewart EW, Paolantonio AR. Effect of variable power levels on the yield of total aerosol mass and formation of aldehydes in e-cigarette aerosols. Regul Toxicol Pharmacol 2016;75:58-65.

25. Uchiyama S, Ohta K, Inaba Y, Kunugita N. Determination of carbonyl compounds generated from the e-cigarette using coupled silica cartridges impregnated with hydroquinone and 2,4-dinitrophenylhydrazine, followed by high-performance liquid chromatography. Anal Sci 2013;29(12):1219-1222.

26. Herrington JS, Myers C. Electronic cigarette solutions and resultant aerosol profiles. J Chromatogr A 2015;1418:192-199.

27. Ingebrethsen BJ, Cole SK, Alderman SL. Electronic cigarette aerosol particle size distribution measurements. Inhal Toxicol 2012;24(14): 976-984.

28. Zhang Y, Sumner W, Chen DR. In vitro particle size distributions in electronic and conventional cigarette aerosols suggest comparable deposition patterns. Nicotine Tob Res 2013;15(2):501-508.

29. Hwang JH, Lyes M, Sladewski K, Enany S, McEachern E, Mathew DP, et al. Electronic cigarette inhalation alters innate immunity and airway cytokines while increasing the virulence of colonizing bacteria. J Mol Med (Berl) 2016 [Epub ahead of print] doi: 10.1007/ s00109-016-1378-3.

30. Farsalinos KE, Romagna G, Allifranchini E, Ripamonti E, Bocchietto $\mathrm{E}$, Todeschi S, et al. Comparison of the cytotoxic potential of cigarette smoke and electronic cigarette vapour extract on cultured myocardial cells. Int J Environ Res Public Health 2013;10(10):51465162.

31. Bahl V, Lin S, Xu N, Davis B, Wang YH, Talbot P. Comparison of electronic cigarette refill fluid cytotoxicity using embryonic and adult models. Reprod Toxicol 2012;34(4):529-537.
32. Wu Q, Jiang D, Minor M, Chu HW. Electronic cigarette liquid increases inflammation and virus infection in primary human airway epithelial cells. PLoS One 2014;9(9):e108342.

33. Vardavas CI, Anagnostopoulos N, Kougias M, Evangelopoulou V, Connolly GN, Behrakis PK. Short-term pulmonary effects of using an electronic cigarette: impact on respiratory flow resistance, impedance, and exhaled nitric oxide. Chest 2012;141(6):1400-1406.

34. Flouris AD, Chorti MS, Poulianiti KP, Jamurtas AZ, Kostikas K, Tzatzarakis MN, et al. Acute impact of active and passive electronic cigarette smoking on serum cotinine and lung function. Inhal Toxicol 2013;25(2):91-101.

35. Czogala J, Goniewicz ML, Fidelus B, Zielinska-Danch W, Travers MJ, Sobczak A. Secondhand exposure to vapors from electronic cigarettes. Nicotine Tob Res 2014;16(6):655-662.

36. Benowitz NL. Cigarette smoking and cardiovascular disease: pathophysiology and implications for treatment. Prog Cardiovasc Dis 2003; 46(1):91-111.

37. St Helen G, Havel C, Dempsey DA, Jacob P 3rd, Benowitz NL. Nicotine delivery, retention, and pharmacokinetics from various electronic cigarettes. Addiction 2016;111(3):535-544.

38. Vansickel AR, Cobb CO, Weaver MF, Eissenberg TE. A clinical laboratory model for evaluating the acute effects of electronic "cigarettes": nicotine delivery profile and cardiovascular and subjective effects. Cancer Epidemiol Biomarkers Prev 2010;19(8):1945-1953.

39. Lopez AA, Hiler MM, Soule EK, Ramôa CP, Karaoghlanian NV, Lipato $\mathrm{T}$, et al. Effects of electronic cigarette liquid nicotine concentration on plasma nicotine and puff topography in tobacco cigarette smokers: a preliminary report. Nicotine Tob Res 2016;18(5): 720-723.

40. Evans SE, Hoffman AC. Electronic cigarettes: abuse liability, topography and subjective effects. Tob Control 2014;23(Suppl2):ii23-9.

41. Vansickel AR, Eissenberg T. Electronic cigarettes: effective nicotine delivery after acute administration. Nicotine Tob Res 2013;15(1): 267-270.

42. Vansickel AR, Weaver MF, Eissenberg T. Clinical laboratory assessment of the abuse liability of an electronic cigarette. Addiction 2012;107(8):1493-1500.

43. Farsalinos KE, Spyrou A, Tsimopoulou K, Stefopoulos C, Romagna G, Voudris V. Nicotine absorption from electronic cigarette use: comparison between first and new-generation devices. Sci Rep 2014; 4:4133.

44. Delnevo CD, Giovenco DP, Steinberg MB, Villanti AC, Pearson JL, Niaura RS, Abrams DB. Patterns of electronic cigarette use among adults in the United States. Nicotine Tob Res 2016;18(5):715-719.

45. Warner KE. Frequency of e-cigarette use and cigarette smoking by American students in 2014. Am J Prev Med 2016 [Epub ahead of print] doi: 10.1016/j.amepre.2015.12.004.

46. Primack BA, Soneji S, Stoolmiller M, Fine MJ, Sargent JD. Progression to traditional cigarette smoking after electronic cigarette use among US adolescents and young adults. JAMA Pediatr 2015; 169(11):1018-1023.

47. Rahman MA, Hann N, Wilson A, Mnatzaganian G, Worrall-Carter L. E-cigarettes and smoking cessation: evidence from a systematic review and meta-analysis. PLoS One 2015;10(3):e0122544.

48. McRobbie H, Bullen C, Hartmann-Boyce J, Hajek P. Electronic cigarettes for smoking cessation and reduction. Cochrane Database Syst Rev 2014;(12):CD010216.

49. Kalkhoran S, Glantz SA. E-cigarettes and smoking cessation in realworld and clinical settings: a systematic review and meta-analysis. Lancet Respir Med 2016;4(2):116-128.

50. Tseng TY, Ostroff JS, Campo A, Gerard M, Kirchner T, Rotrosen J, Shelley D. A randomized trial comparing the effect of nicotine versus placebo electronic cigarettes on smoking reduction among young 


\section{E-Cigarettes: The Science Behind the Smoke and Mirrors}

adult smokers. Nicotine Tob Res 2016 [Epub ahead of print] doi: 10.1093/ntr/ntw017.

51. Nutt DJ, Phillips LD, Balfour D, Curran HV, Dockrell M, Foulds J, et al. Estimating the harms of nicotine-containing products using the MCDA approach. Eur Addict Res 2014;20(5):218-225.

52. Lynch R. Are smokeless cigarettes safer? E-cig explodes in smoker's mouth. Los Angeles Times. February 16, 2012. http://latimesblogs.latimes.com/nationnow/2012/02/electronic-cigarette-explodesmans-mouth.html Accessed March 4, 2012.

53. Colaianni CA, Tapias LF, Cauley R, Sheridan R, Schulz JT, Goverman J. Injuries caused by explosion of electronic cigarette devices. Eplasty 2016;16:ic9.

54. Williams M, Villarreal A, Bozhilov K, Lin S, Talbot P. Metal and silicate particles including nanoparticles are present in electronic cigarette cartomizer fluid and aerosol. PLoS One 2013;8(3): e57987.
55. Jensen RP, Luo W, Pankow JF, Strongin RM, Peyton DH. Hidden formaldehyde in e-cigarette aerosols. N Engl J Med 2015;372(4):392-394.

56. McCauley L, Markin C, Hosmer D. An unexpected consequence of electronic cigarette use. Chest 2012;141(4):1110-1113.

57. Cobb NK, Abrams DB. The FDA, e-cigarettes, and the demise of combusted tobacco. N Engl J Med 2014;371(16):1469-1471.

58. Deeming tobacco products to be subject to the Federal Food, Drug, and Cosmetic Act, as amended by the family smoking prevention and tobacco control act: regulations on the sale and distribution of tobacco products and required warning statements for tobacco products. Federal Register 2014;79:23141-23207.

59. West R, Shahab L, Brown J. Estimating the population impact of e-cigarettes on smoking cessation in England. Addiction 2016;111(6): 1118-1119.

60. Koh HK, Sebelius KG. Promoting prevention through the Affordable Care Act. N Engl J Med 2010;363(14):1296-1299. 